\title{
PHYLOGENETIC ANALYSIS OF HUMAN BOCAVIRUS IN CHILDREN WITH ACUTE RESPIRATORY INFECTIONS IN IRAN
}

\author{
Mehrdad MOHAMMAdi $^{1}$, Jila YAVARIAN ${ }^{2}$, VAJiHe KARBASIZAdE ${ }^{1}$, \\ SHARAREH MOGHIM $^{1 *}$, BAHRAM NASR ESFAHANI ${ }^{1}$ and \\ NAFISEH SADAT HOSSEINI ${ }^{1}$ \\ ${ }^{1}$ Department of Microbiology, Isfahan University of Medical Sciences, Isfahan, Iran \\ ${ }^{2}$ Department of Virology, School of Public Health, Tehran University of Medical \\ Sciences, Tehran, Iran
}

(Received: 18 February 2019; accepted: 10 April 2019)

\begin{abstract}
Human bocavirus ( $\mathrm{HBoV}$ ) was first characterized in nasopharyngeal aspirates from young children with acute respiratory infections. It is prevalent among children with acute wheezing. This study was carried out in order to analyze the infection frequency and coinfection rates of $\mathrm{HBoV}$ with respiratory syncytial virus (RSV) and to perform phylogenetic analysis of $\mathrm{HBoV}$ in samples of children with acute respiratory infection in Isfahan, Iran. During the time period 2016-2017, altogether 75 respiratory samples from children hospitalized with acute respiratory infection were collected. The samples were first screened for RSV by direct immunofluorescence method and then subjected to detect HBoV DNA by PCR. Genotyping of $\mathrm{HBoV}$-positive samples was conducted by direct sequencing of $\mathrm{PCR}$ products using NP and VP1/VP2 genes. Out of 75 respiratory samples, $20(26.7 \%)$ and $10(13.3 \%)$ were positive for RSV and $\mathrm{HBoV}$, respectively. The coinfection rate was $40 \%$ $(p=0.048)$. Considering the seasonal distribution, winter has the highest extent outbreak $(p=0.036)$. Sequence analysis of positive samples exhibits that all of the isolated $\mathrm{HBoV}$ were related to genotype 1 (HBoV-1) with minimal sequence variations. Increasing frequency of $\mathrm{HBoV}$ suggests that the virus is related to acute respiratory infection in children. A single genetic lineage of $\mathrm{HBoV} 1$ seems to be the major genotype in Iran.
\end{abstract}

Keywords: human bocavirus, acute respiratory tract infection, respiratory syncytial virus, phylogenetic analysis, Iran

*Corresponding author; E-mail: moghim@med.mui.ac.ir 


\section{Introduction}

Acute respiratory tract infections (ARTIs) are the frequently diagnosed diseases for hospitalization, particularly in infants and young children $[1,2]$. The disease is the main cause of morbidity and mortality, estimating 3.5 million deaths worldwide [2]. Viral pathogens play an important role in ARTI [3]. A heterogeneous group of respiratory viruses, including some of the most notable RNA viruses, such as respiratory syncytial virus (RSV), influenza virus, parainfluenza virus, metapneumovirus, rhinovirus $(\mathrm{RhV})$, and coronavirus are responsible for acute respiratory illnesses. RSV is the most prevalent virus involved in ARTIs [1-3]. Human bocavirus (HBoV), a member of Parvoviridae family, was first identified in 2005 in Sweden using a protocol based on DNase treatment, random polymerase chain reaction (PCR) amplification, intensewidely sequencing, and bioinformatics interpretation [4]. Its classification as bocavirus is based on similarities of the genetic structures and amino acid sequences with bovine parvovirus and canine minute virus [5-7]. PCR techniques enable detection of $\mathrm{HBoV}$ genome fragments from nasopharyngeal aspirates, bronchoalveolar lavages, feces, serum and urine samples using amplification of NP1, NS1 or/and the VP1/2 gene, or other nucleic acid-based determination methods [8-10]. HBoV clinical manifestations might vary in infants and toddlers and include fever, wheezing, coughing, and rhinorrhea $[11,12]$. There are four major HBoV genotypes, such as $\mathrm{HBoV} 1-4$ [13]. $\mathrm{HBoV}-1$ has been mainly identified in respiratory samples, whereas $\mathrm{HBoV} 2-4$ are chiefly identified in stool samples, indicating to cause gastrointestinal infections [13]. HBoV has a worldwide distribution [7, 13]. The virus is extensively circulating throughout the year, although it is more predominant in spring and winter [7, 13, 14]. The average prevalence of $\mathrm{HBoV}$ is $1.0 \%-56.8 \%$ in respiratory samples and $1.3 \%-63 \%$ in stool specimens of children with acute gastroenteritis [5, 13]. Coinfection between $\mathrm{HBoV}$ and other respiratory pathogens, such as RSV, and human $\mathrm{RhV}$ is frequent. Infants with coinfections (RSV and $\mathrm{HBoV}$ ) have shown higher clinical severity than infants with RSV, RV, and BoV infections [15-17]. Notably, coinfecting pathogens have been found in up to $83 \%$ of respiratory samples [18]. The most typical age for $\mathrm{HBoV}$ infection is less than 2 years; rarely, it has been found in adults and the older people $[7,13]$. The main goals of this report were to find the frequency of $\mathrm{HBoV}$ in children less than 3 years, to characterize its seasonal distribution, and to carry out phylogenetic analysis of $\mathrm{HBoV}$ strains circulating in Isfahan, Iran. We also studied the coinfection rates of the virus with the most prevalent respiratory pathogen, RSV. 


\section{Materials and Methods}

\section{Patients and clinical samples}

This cross-sectional study was carried out between 2016 and 2017 at teaching hospital, which is affiliated to Isfahan University of Medical Sciences (Imam Hussein Central Pediatric Hospital). Nasopharyngeal swabs collected from children less than 3 years old with symptoms of respiratory tract infection, including fever, wheezing, coughing, hypoxia, dyspnea, and rhinorrhea. The specimens were immediately transported in cold boxes $\left(2-8{ }^{\circ} \mathrm{C}\right)$ to the virology laboratory. The nasopharyngeal swabs then divided into two aliquots: one treated for nucleic acid extraction and the second was immediately centrifuged at 3,000 $\mathrm{rpm}$ for $10 \mathrm{~min}$ to pellet the infected cells and stored at $-70{ }^{\circ} \mathrm{C}[19]$.

\section{Detection of RSV}

For detection of RSV antigens in respiratory samples, direct immunofluorescence technique [20] was performed using RSV commercial kit (Euroimmun RSV, USA), according to the manufacturer's instruction. Briefly, secretions from the nasopharyngeal region were collected into a mucus extractor through a size 8 feeding tube. The mucus extractor and tubing were transmitted to the laboratory for processing. In order to dilute the mucus, $2 \mathrm{ml}$ phosphate buffered saline (PBS) was added to the tube and centrifuged for $10 \mathrm{~min}$ at $380 \times \mathrm{g}$. The pellet was suspended in $0.5 \mathrm{ml}$ PBS by gently pipetting and $25 \mu \mathrm{l}$ of the resuspended cell deposit was added to the slide. The specimen was air-dried thoroughly and fixed with fresh acetone at room temperature for $10 \mathrm{~min}$. The fixed slides were stained with conjugated purified murine monoclonal antibodies directed against the fusion protein and nucleoprotein of RSV, mounted, and visualized through epifluorescence microscope (Olympus EX51, Japan).

\section{Detection of $\mathrm{HBoV}$}

Viral nucleic acids were extracted from respiratory secretion using viral nucleic acid extraction kit (DynaBio ${ }^{\mathrm{TM}}$, Iran), according to manufacturer's protocol. All samples were screened for $\mathrm{HBoV}$ using PCR method by primers detecting the NP-1 coding region. The primers sequences were as follows: F: 5'-AGCTCTGTAAGTACTATTAC-3' and R: 5'-CTCTGTGTTGACTGAATACAG-3' [21]. PCR condition was as follows: initial denaturation at $94{ }^{\circ} \mathrm{C}$ for $5 \mathrm{~min}$, followed by 40 cycles of denaturation at $94{ }^{\circ} \mathrm{C}$ for $1 \mathrm{~min}$, annealing at $54{ }^{\circ} \mathrm{C}$ 
for $1 \mathrm{~min}$, extension at $72{ }^{\circ} \mathrm{C}$ for $2 \mathrm{~min}$, and a final extension at $72{ }^{\circ} \mathrm{C}$ for $10 \mathrm{~min}$. The amplicons were visualized on $1.5 \%$ agarose gel stained with SYBR Safe DNA gel stain (ThermoFisher Scientific, USA). A cloned plasmid pTZ, containing HBoV NP-1 gene (Invitrogen, Carlsbad, CA, USA), was confirmed by sequencing and used as positive control.

\section{HBoV genotyping}

For genotyping, DNA of all $\mathrm{HBoV}$ positive samples was amplified by conventional PCR assay. Briefly, a set of forward (5'-GGACCACAGTCATCAGAC-3') and reverse primers (5'-CCACTACCATCGGGCTG-3') were used to target 820 bp of the HBoV VP2 gene junction [22]. The thermal cycling conditions were as follows: an initial denaturation of $5 \mathrm{~min}$ at $94{ }^{\circ} \mathrm{C}$, followed by 40 cycles of $1 \mathrm{~min}$ at $94{ }^{\circ} \mathrm{C}, 1 \mathrm{~min}$ at $54^{\circ} \mathrm{C}, 2 \mathrm{~min}$ at $72^{\circ} \mathrm{C}$, and the final extension of $10 \mathrm{~min}$ at $72{ }^{\circ} \mathrm{C}$. The PCR products were purified and subjected for sequencing, (Bioneer Inc., Korea).

\section{Phylogenetic analysis}

All alignments were performed using Chromas Pro software program (version 2.1.3; Techelysium Pty Ltd., South Brisbane, QLD, Australia). Phylogenetic trees of the NP-1 and VP-2 genes generated using the neighbor-joining and maximum likelihood methods and Kimura 2-parameter algorithm of MEGA software (version 6.0; Pennsylvania, USA). Bootstrap probabilities for 1,000 literations were calculated to check confidence estimates. Only those samples that showed the same genotype in both methods were included for inference. The nucleotide sequences of NP1 and VP1/VP2 sequences were compared with those of reference strains available in NCBI website using BLASTN. The partial sequences of VP1/VP2 gene were submitted to GenBank (accession numbers: MH574941-MH574945).

\section{Statistical analysis}

Data were processed using SPSS statistical software program version 16.0 (IBM, SPSS statistics, Chicago, IL, USA). The correlations were subjected to the Pearson's $\chi^{2}$ test. Statistical significance is set at a $p$ value of less than 0.05 .

\section{Ethical approval}

This work was in accordance with the ethical standards of Ethics Committee of the Isfahan University of Medical Sciences (9604-396486). Informed parental consent was obtained from all participants. 


\section{Results}

\section{Detection of RSV}

In total, 75 respiratory samples were collected from children less than 3 years old admitted to the referred hospital in Isfahan, Iran. Twenty (26.7\%) of the specimens were positive for RSV (Figure 1). Twelve (60\%) positive samples were collected from females and $8(40 \%)$ were collected from males. No statistical significance was found regarding RSV infections and gender $(p=0.512)$. The age distribution showed that 7 (35\%) of RSV-positive samples were from children between 1 and 2 years old. The statistical significance was meaningful regarding RSV and age $(p=0.032)$. The prevalence of ARTIs caused by RSV has a major peak in winter, especially in January and February (Figure 2). In this study, 11 positive cases $(55 \%)$ were collected in winter. There was meaningful statistical significance regarding the RSV infection and season $(p=0.039)$.

\section{Detection of $\mathrm{HBOV}$}

Presence of $\mathrm{HBoV}$ in specimens was evaluated by PCR method. Among the 75 collected respiratory samples, HBoV DNA was found in $10(13.3 \%)$ samples. The size of the PCR product including the fragment of the NP1 gene was $354 \mathrm{bp}$ (Figure 3). There was no statistical significance regarding $\mathrm{HBoV}$ infection and gender $(p=0.506)$. Among HBoV-infected children, $40 \%$ were between 1 and 2 years old, followed by $30 \%$ under 6 months, $0 \%$, between 6 months and 1 year,

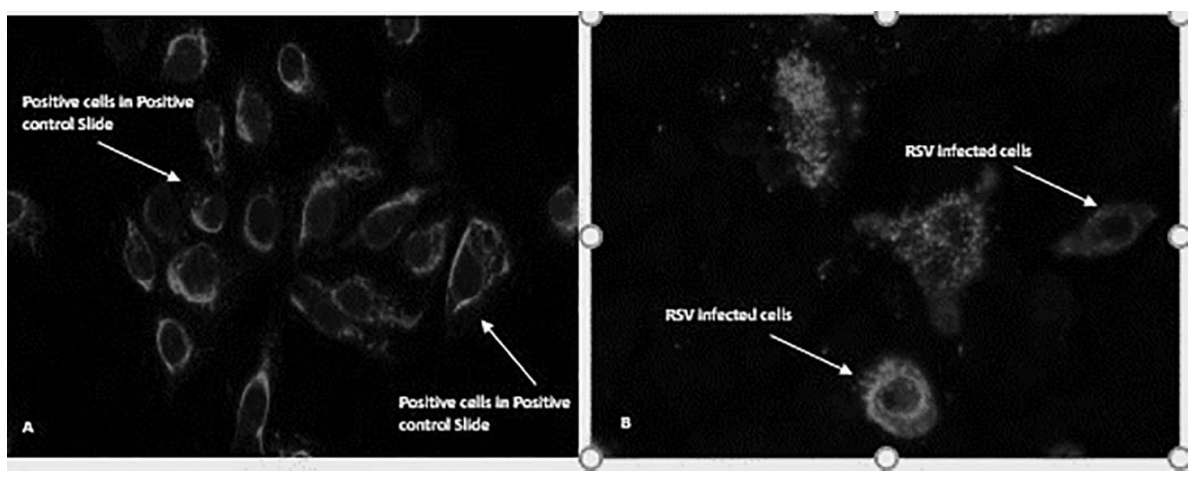

Figure 1. Epithelial cells in nasopharyngeal swabs specimen from a positive control (A) and patient with RSV infection (B), showing specific RSV fluorescence after monoclonal antibody staining against F/NP. White arrows show the staining of prominent RSV inclusions $(40 \times)$ 


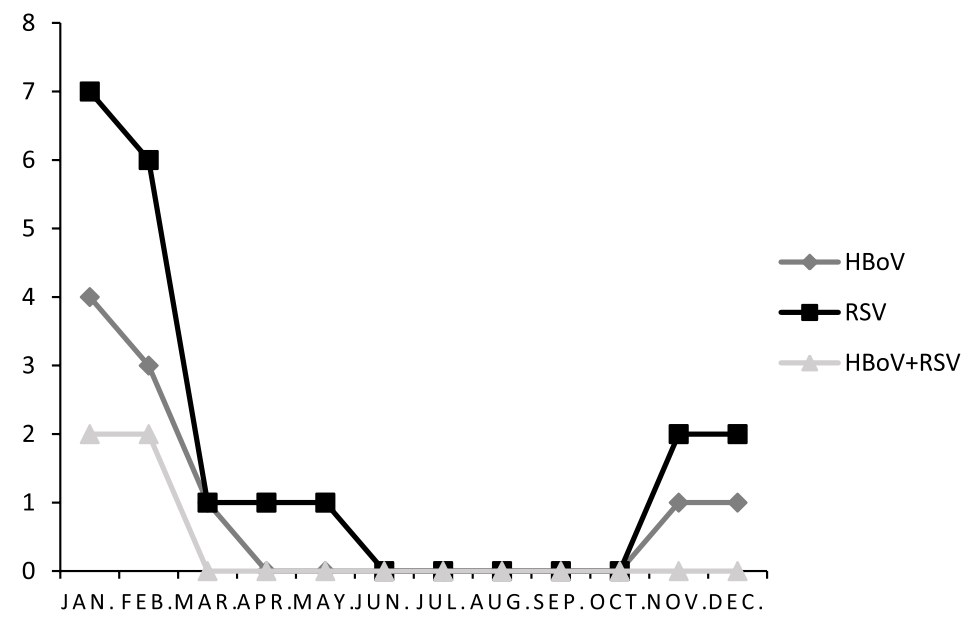

Figure 2. Monthly distribution of HBoV, RSV, and RSV/HBoV coinfection. HBoV: human bocavirus; RSV: respiratory syncytial virus $(p<0.025)$

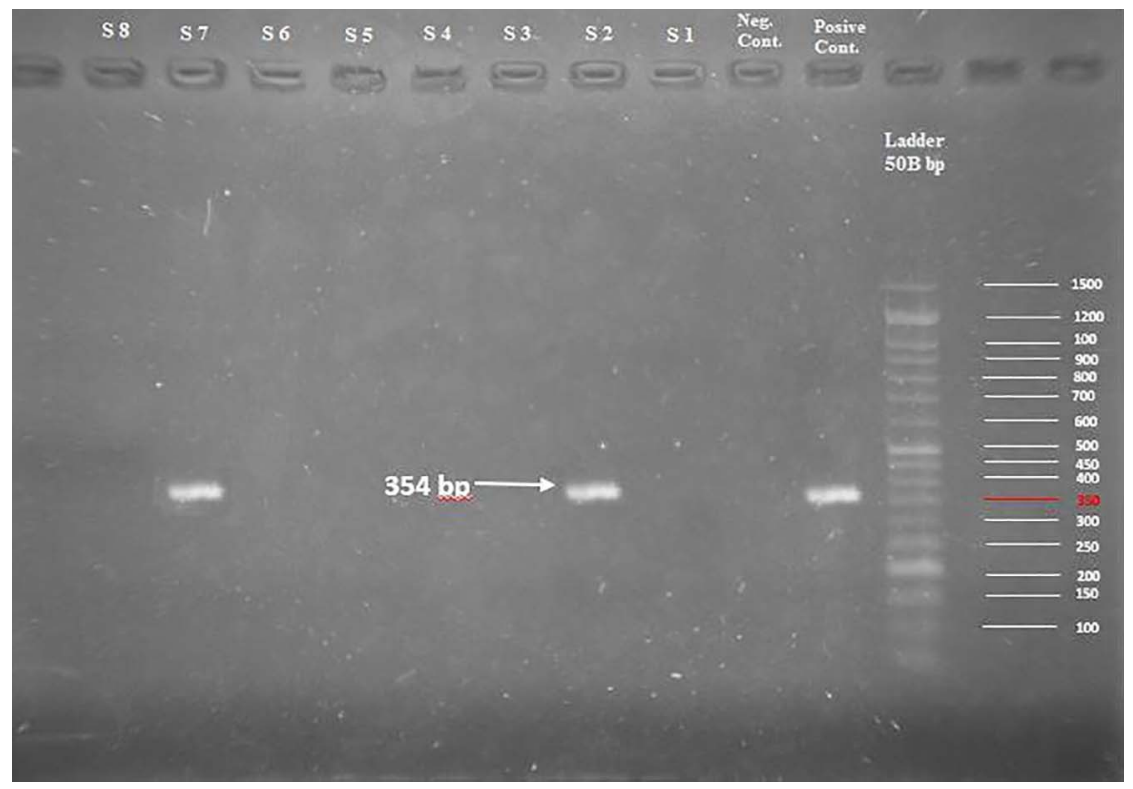

Figure 3. Analysis of NP-1 PCR products by agarose gel electrophoresis. Viral nucleic acids extracted from respiratory secretion were amplified using PCR. Lanes 2 and 7: two positive samples; Lanes 1, 4-6, and 8: five negative samples; negative control and positive control. NP-1: nucleoprotein 1 
and $30 \%$ between 2 and 3 years $(p=0.037)$. Among $10 \mathrm{HBoV}$-positive samples, 9 $(90 \%)$ were collected in winter. This showed that the prevalence of $\mathrm{HBoV}$ infections has a major peak in winter $(p=0.036$; Figure 2).

\section{$R S V$ and $H B o V$ dual infections}

Comparing the patient groups according to the type of virus (RSV, HBoV, and $\mathrm{HBoV}+\mathrm{RSV}$ coinfection), several differences were identified between the groups. Mean age of children was different between RSV and HBoV mono-infection group and RSV/HBoV coinfection. Children with RSV and HBoV single infection were older than $\mathrm{RSV} / \mathrm{HBoV}$ coinfection group $(p=0.037)$. Clinical symptoms such as fever and rhinorrhea were not significant $(p>0.05)$. There was meaningful statistical significance regarding clinical symptoms, including wheezing $(p=0.002)$, cough $(p=0.021)$, dyspnea $(p=0.048)$, and $\mathrm{HBoV}$ infection $(p=0.048)$. Dyspnea $(40 \% ; p=0.002)$ was the most common symptom in the $\mathrm{HBoV}$ group and coughing $(90 \% ; p=0.021)$ was the most frequent symptom in $\mathrm{RSV} / \mathrm{HBoV}$ coinfection group (Table I).

\section{Phylogenetic analysis}

Two PCR products of NP-1 gene were confirmed by sequencing. The results of sequences were compared with 34 reference sequences including strains from

Table I. Clinical and demographic characteristics in children with acute respiratory infections regarding the identified viruses

\begin{tabular}{|c|c|c|c|c|}
\hline Clinical features & $\operatorname{RSV}(n=75)$ & $\mathrm{HBoV}(n=10)$ & $\mathrm{RSV}+\operatorname{HBoV}(n=4)$ & $p$ value \\
\hline Male & $8(40 \%)$ & $5(50 \%)$ & $1(25 \%)$ & 0.506 \\
\hline Female & $12(60 \%)$ & $5(50 \%)$ & $3(75 \%)$ & \\
\hline $37.9<$ fever & $19(95 \%)$ & $5(50 \%)$ & $3(75 \%)$ & 0.469 \\
\hline Wheezing & $10(50 \%)$ & $7(70 \%)$ & $3(75 \%)$ & $0.002 *$ \\
\hline Cough & $16(80 \%)$ & $9(90 \%)$ & $3(75 \%)$ & $0.021 *$ \\
\hline Rhinorrhea & $15(75 \%)$ & $7(70 \%)$ & $4(100 \%)$ & 0.407 \\
\hline Hypoxia $\left(\mathrm{SatO}_{2}<95 \%\right)$ & $5(25 \%)$ & $4(40 \%)$ & $2(50 \%)$ & 0.105 \\
\hline Dyspnea & $4(20 \%)$ & $4(40 \%)$ & $1(25 \%)$ & $0.048 *$ \\
\hline Age: $<6$ months & $5(25 \%)$ & $3(30 \%)$ & $2(50 \%)$ & $0.037 *$ \\
\hline Age: 6 months -1 year & $2(10 \%)$ & 0 & 0 & \\
\hline Age: $1-2$ years & $7(35 \%)$ & $4(40 \%)$ & $1(25 \%)$ & \\
\hline Age: $2-3$ years & $6(30 \%)$ & $3(30 \%)$ & $1(25 \%)$ & \\
\hline
\end{tabular}

Note: RSV: respiratory syncytial virus; $\mathrm{HBoV}$ : human bocavirus.

${ }^{*} p$ values $<0.05$ were considered to be statistical significant. 


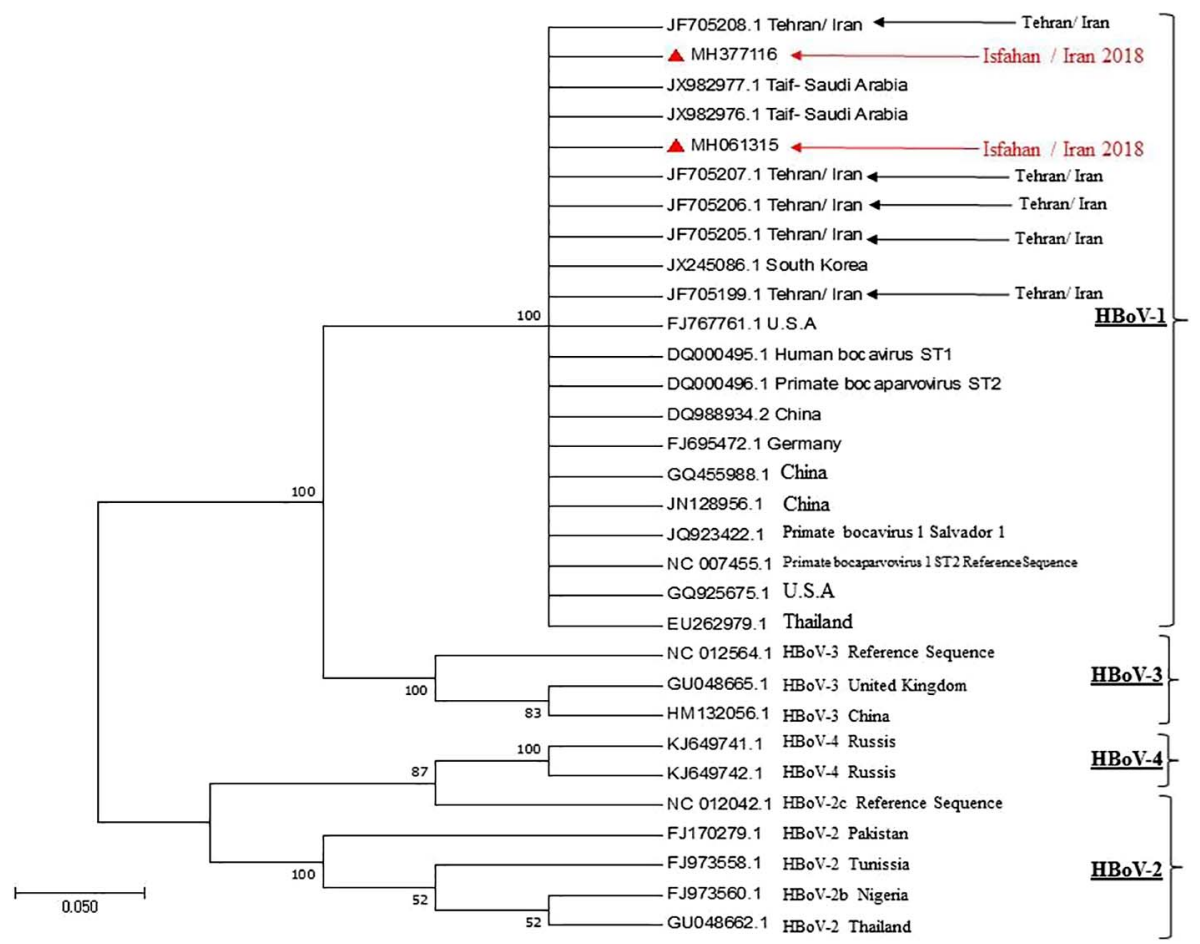

Figure 4. Phylogenetic tree based on gene sequences encoding the HBoV polyprotein NP1 of HBoV isolates. The red triangle represents sequences originating from our studies (MH377116 and MH061315). HBoV1-4 standard genotypes were represented in squares: Black is related to HBoV-1, purple related to $\mathrm{HBoV}-2$, turquoise related to $\mathrm{HBoV}-3$, and blue related to $\mathrm{HBoV}-4$ genotypes. The percentage of replicate trees in which the taxa are clustered in test (1,000 replicates bootstrapping) is shown next to the branch

the four $\mathrm{HBoV}$ genotypes registered in the GenBank database (https://www. ncbi.nlm.nih.gov/genbank/). Phylogenetic analysis of the partial NP1 gene confirmed that these two isolates are $\mathrm{HBoV}$ and belong to genotype 1 (Figure 4). The sequenced NP-1 gene was submitted to GenBank with following accession numbers: MH377116 and MH061315. Because VP1/VP2 gene has the greatest variation in the $\mathrm{HBoV}$ genome, especially at its $3^{\prime}$ end [23], all HBoV-positive specimens were selected to amplify VP1/VP2 partial gene sequences and aligned with 44 reference sequences including HBoV1-4, porcine, bovine, and canine parvoviruses. Phylogenetic analysis of VP1/VP2 region indicated that all $\mathrm{HBoV}$ isolates in this study in the isolated strains were in the same cluster as other strain from Iran (Figure 5). 


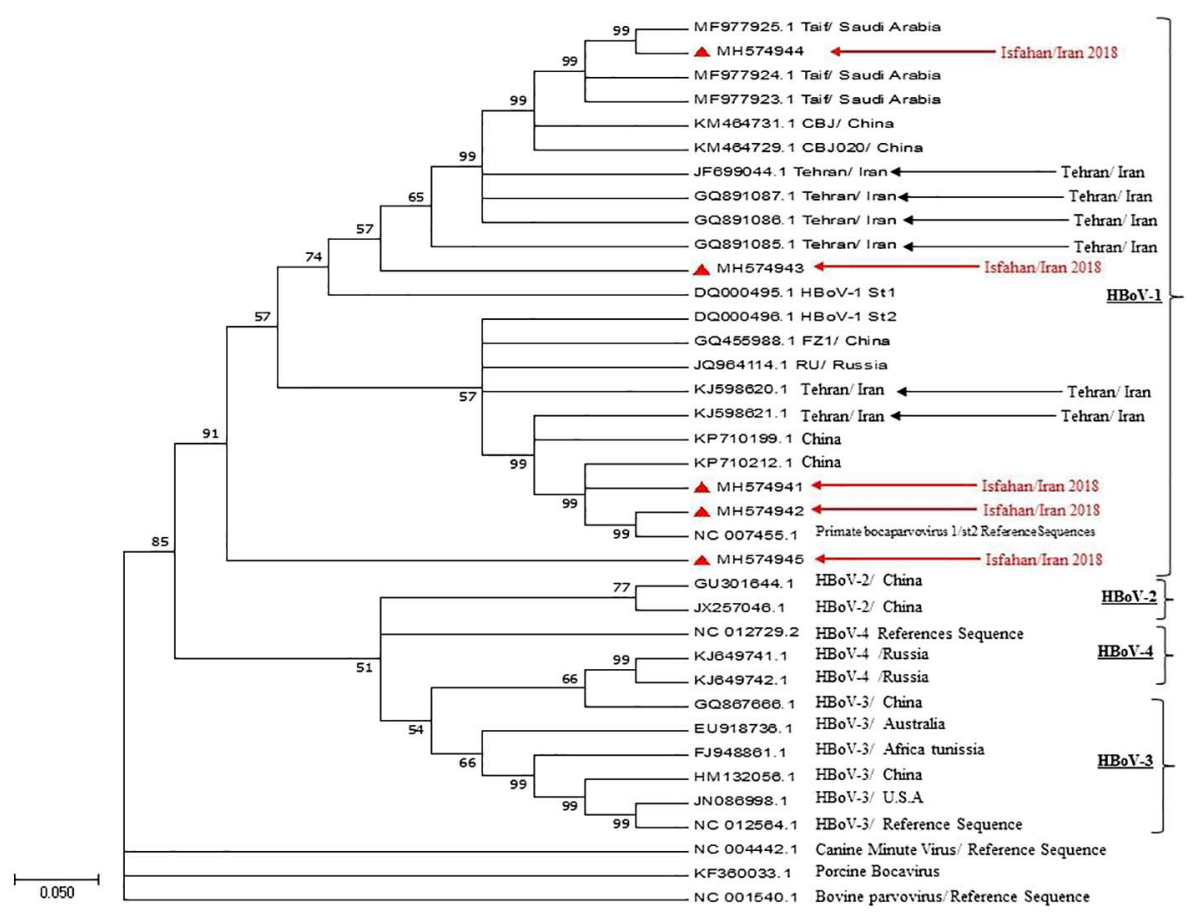

Figure 5. Phylogenetic tree constructed from the VP1/VP2 gene sequences of HBoV strains from respiratory samples. The red triangles represent strains from children with acute respiratory infection (GenBank accession numbers: MH574941, MH574942, MH574943, MH574944, and MH574945)

\section{Discussion}

Since the discovery of $\mathrm{HBOV}$ by Allander, rising reports have shown that $\mathrm{HBoV}$ is involved in upper and lower respiratory tract infections [4, 6]. HBoV has been detected in $1.5 \%-19 \%$ of respiratory tract samples from young children with respiratory infections [13]. Reports from New Zealand, North America, Europe, Asia, and Africa confirm the global distribution and indicate increasing frequency of the virus worldwide [24-27]. In this study, HBoV was detected in 10 of 75 (13.3\%) respiratory samples. In accordance with this study, the prevalence of $\mathrm{HBoV}$ infections in some regions of Iran was also evaluated. The prevalence has been reported $8 \%$ in a northern city of Iran (2003-2004) [28], 6.8\% in Tehran (2006-2008) [29], and 10.7\% (2012-2013) in Tehran [30]. The minor difference in frequency could be related to the number of patients studied, time of collecting the samples, geographical locations, and the age groups studied. In addition, it seems that the prevalence and distribution of the virus is increasing. Although 
RSV is the major pathogen in infants less than 1 year old, the rate of $\mathrm{HBoV}$ infection was also meaningful and the pathogenic potential of this virus could not be ignored.

The most common symptoms of acute viral respiratory infections are wheezing, cough, dyspnea, and fever [31]. HBoV is prevalent among children with acute wheezing $[8,12,13]$. We reported that major symptoms in RSV, $\mathrm{HBoV}$ mono-, and coinfections were different. The most frequent clinical manifestations in HBoV group were wheezing and dyspnea. This could explain why pneumonia is much more frequent in children infected with $\mathrm{HBoV}$ [12-14]. RSV and HBoV coinfection shared clinical symptoms of both viruses, with wheezing as the most frequent clinical symptom. This result is in agreement with other studies that outline $\mathrm{HBoV}-1$ is able to infect the lower respiratory tract down to bronchioles [12].

The acute respiratory infections usually occur from late fall to early spring $[7,13]$. Seasonal peaks of $\mathrm{HBoV}$ infection vary among different countries because of different climate and geographic conditions. Previous studies suggested that $\mathrm{HBoV}$ infection had a higher detection rate in winter $[7,12,13]$. In this study, a higher frequency of HBoV infection was observed between January and March with a peak in February. Bocavirus is often found in mixed infections with other viruses [15]. Prevalence of HBoV seasonally coincides with RSV [15-20]. Therefore, we studied RSV as one of the most commonly associated infectious agents in ARTI. We reported the coinfection rate of $40 \%$. The studies in other regions of Iran described lower coinfection rates with RSV [28, 29], whereas in other countries, a high proportion of coinfections with other viruses have been observed [27, 31, 32]. This considerable coinfection rate further supported the idea that $\mathrm{HBoV}$ might be a bystander in respiratory infection.

Based on Vp1/VP2 gene sequences, all HBoV strains isolated in this study were related to $\mathrm{HBoV}-1$. Although very low variability exists in $\mathrm{HBoV}$ genomic region encoding capsid proteins, all our isolates were in the same cluster as the original isolates of ST1 (Stockholm 1; 5,217 nt; accession no. DQ000495) and ST2 (Stockholm 2; 5,299 nt; accession no. DQ000496) [4]. Moreover, other $\mathrm{HBoV}$ strains identified in Iran and some countries in the region are in the same cluster (Figure 5) [30, 32]. This proposes that relative $\mathrm{HBoV}-1$ strains are circulating in this geographical region.

According to our results, the frequency of $\mathrm{HBoV}$ infections/circulation in Iran is increasing. This virus might play a significant role in ARTIs, as a major cause or coinfection with RSV. All the strains detected in respiratory tract infections belonged to $\mathrm{HBoV}$ genotype 1. Further studies on the clinical relevance of $\mathrm{HBoV}$ in respiratory tract infections are needed. 


\section{Acknowledgements}

This work was supported by a grant (396486) from the Isfahan University of Medical Sciences. The authors would like to thank Maryam Tabasi, School of Medical science, Jundishapour University of Medical Sciences, for providing HBoV-positive control.

\section{Conflict of Interest}

The authors have no potential conflict of interest to declare.

\section{References}

1. Bicer, S., Giray, T., Çöl, D., Erdağ, G. Ç., Vitrinel, A., Gürol, Y., Çelik, G., Kaspar, Ç., Küçük, Ö.: Virological and clinical characterizations of respiratory infections in hospitalized children. Ital J Pediatr 39, 22 (2013).

2. Cebey-López, M., Herberg, J., Pardo-Seco, J., Gómez-Carballa, A., Martinón-Torres, N., Salas, A., Martinón-Sánchez, J. M., Gormley, S., Sumner, E., Fink, C., Martinón-Torres, F., GENDRES network: Viral co-infections in pediatric patients hospitalized with lower tract acute respiratory infections. PLoS One 10, e0136526 (2015).

3. Debiaggi, M., Canducci, F., Ceresola, E. R., Clementi, M.: The role of infections and coinfections with newly identified and emerging respiratory viruses in children. Virol $\mathrm{J}$ 9, 247 (2012).

4. Allander, T., Tammi, M. T., Eriksson, M., Bjerkner, A., Tiveljung-Lindell, A., Andersson, B.: Cloning of a human parvovirus by molecular screening of respiratory tract samples. Proc Natl Acad Sci U S A 102, 12891-12896 (2005).

5. Cotmore, S. F., Agbandje-McKenna, M., Chiorini, J. A., Mukha, D. V., Pintel, D. J., Qiu, J., Soderlund-Venermo, M., Tattersall, P., Tijssen, P., Gatherer, D., Davison, A. J.: The family Parvoviridae. Arch Virol 159, 1239-1247 (2014).

6. Allander, T.: Human bocavirus. J Clin Virol 41, 29-33 (2009).

7. Jartti, T., Hedman, K., Jartti, L., Ruuskanen, O., Allander, T., Soderlund-Venermo, M.: Human bocavirus-the first 5 years. Rev Med Virol 22, 46-64 (2012).

8. Babkin, I. V., Tyumentsev, A. I., Tikunov, A. Y., Zhirakovskaia, E. V., Netesov, S. V., Tikunova, N. V.: A study of the human bocavirus replicative genome structures. Virus Res 195, 196-202 (2015).

9. Schildgen, O., Qiu, J., Soderlund-Venermo, M.: Genomic features of the human bocaviruses. Future Virol 7, 31-39 (2012).

10. Allander, T., Jartti, T., Gupta, S., Niesters, H. G., Lehtinen, P., Vuorinen, T., Waris, M., Bjerkner, A., Tiveljung-Lindell, A., van den Hoogen, B. G.: Human bocavirus and acute wheezing in children. Clin Infect Dis 44, 904-910 (2007).

11. Jiang, W., Yin, F., Zhou, W., Yan, Y., Ji, W.: Clinical significance of different virus load of human bocavirus in patients with lower respiratory tract infection. Sci Rep 6, 20246 (2016). 
12. Guido, M., Tumolo, M. R., Verri, T., Romano, A., Serio, F., De Giorgi, M., De Donno, A., Bagordo, F., Zizza, A.: Human bocavirus: Current knowledge and future challenges. World J Gastroenterol 22, 8684-8697 (2016).

13. Broccolo, F., Falcone, V., Esposito, S., Toniolo, A.: Human bocaviruses: Possible etiologic role in respiratory infection. J Clin Virol 72, 75-81 (2015).

14. Calvo, C., García-García, M. L., Pozo, F., Paula, G., Molinero, M., Calderón, A., GonzálezEsguevillas, M., Casas, I.: Respiratory syncytial virus coinfections with rhinovirus and human bocavirus in hospitalized children. Medicine 94, e1788 (2015).

15. Midulla, F., Scagnolari, C., Bonci, E., Pierangeli, A., Antonelli, G., De Angelis, D., Berardi, R., Moretti, C.: Respiratory syncytial virus, human bocavirus and rhinovirus bronchiolitis in infants. Arch Dis Child 95, 35-41 (2010).

16. Calvo, C., Garcia-Garcia, M. L., Pozo, F., Carballo, D., Martinez-Monteserin, E., Casas, I.: Infections and coinfections by respiratory human bocavirus during eight seasons in hospitalized children. J Med Virol 88, 2052-2058 (2016).

17. Zhou, J. Y., Peng, Y., Peng, X. Y., Gao, H. C., Sun, Y. P., Xie, L. Y., Zhong, L. L., Duan, Z. J., Xie, Z. P., Cao, Y. D.: Human bocavirus and human metapneumovirus in hospitalized children with lower respiratory tract illness in Changsha, China. Influenza Other Respir Viruses 12, 279-286 (2018).

18. Gill, P. J., Richardson, S. E., Ostrow, O., Friedman, J. N.: Testing for respiratory viruses in children: To swab or not to swab. JAMA Pediatr 171, 798-804 (2017).

19. Thomas, E. E., Book, L. E.: Comparison of two rapid methods for detection of respiratory syncytial virus (RSV) (Testpack RSV and ortho RSV ELISA) with direct immunofluorescence and virus isolation for the diagnosis of pediatric RSV infection. J Clin Microbiol 29, 632-635 (1991).

20. Koseki, N., Teramoto, S., Kaiho, M., Gomi-Endo, R., Yoshioka, M., Takahashi, Y., Nakayama, T., Sawada, H., Konno, M., Ushijima, H., Kikuta, H., Ariga, T., Ishiguro, N.: Detection of human bocaviruses 1 to 4 from nasopharyngeal swab samples collected from patients with respiratory tract infections. J Clin Microbiol 50, 2118-2121 (2012).

21. Abdel-Moneim, A. S., Kamel, M. M., Hamed, D. H., Hassan, S. S., Soliman, M. S., Al-Quraishy, S. A., El Kholy, A. A.: A novel primer set for improved direct gene sequencing of human bocavirus genotype-1 from clinical samples. J Virol Methods 228, 108-113 (2016).

22. Bastien, N., Brandt, K., Dust, K., Ward, D., Li, Y.: Human bocavirus infection, Canada. Emerg Infect Dis 12, 848-850 (2006).

23. Kesebir, D., Vazquez, M., Weibel, C., Shapiro, E. D., Ferguson, D., Landry, M. L., Kahn, J. S.: Human bocavirus infection in young children in the United States: Molecular epidemiological profile and clinical characteristics of a newly emerging respiratory virus. J Infect Dis 194, 1276-1282 (2006).

24. Petrarca, L., Nenna, R., Frassanito, A., Pierangeli, A., Cangiano, G., Calicchia, I., Lo Russo, L., Di Mario, C., Faiola, G., Midulla, F.: Human bocavirus and respiratory tract infection in hospitalized children. Eur Respir J 48 (2016).

25. Redshaw, N., Wood, C., Rich, F., Grimwood, K., Kirman, J. R.: Human bocavirus in infants, New Zealand. Emerg Infect Dis 13, 1797-1799 (2007).

26. Zeng, M., Zhu, Q. R., Wang, X. H., Yu, H., Shen, J.: Human bocavirus in children with respiratory tract infection in Shanghai: A retrospective study. World J Pediatr 6, 65-70 (2010). 
27. Naghipour, M., Cuevas, L. E., Bakhshinejad, T., Dove, W., Hart, C. A.: Human bocavirus in Iranian children with acute respiratory infections. J Med Virol 79, 539-543 (2007).

28. Nadji, S. A., Poos-Ashkan, L., Khalilzadeh, S., Baghaie, N., Shiraghaei, M. J., Hassanzad, M., Bolursaz, M. R.: Phylogenetic analysis of human bocavirus isolated from children with acute respiratory illnesses and gastroenteritis in Iran. Scand $\mathbf{J}$ Infect Dis 42, 598-603 (2010).

29. Tabasi, M., Mokhtari-Azad, T., Eshraghian, M. R., Shadab, A., Shatizadeh, S., Shafiei-Jandaghi, N. Z., Yavarian, J.: Human bocavirus infections among children less than two years old in Iran during fall and winter 2012-2013. Iran J Microbiol 8, 80-84 (2016).

30. Abdel-Moneim, A. S., Kamel, M. M., Al-Ghamdi, A. S., Al-Malky, M. I.: Detection of bocavirus in children suffering from acute respiratory tract infections in Saudi Arabia. PLoS One 8, e55500 (2013).

31. Lee, E. J., Kim, H. S., Kim, H. S., Kim, J. S., Song, W., Kim, M., Lee, Y. K., Kang, H. J.: Human bocavirus in Korean children with gastroenteritis and respiratory tract infections. Biomed Res Int 2016, 7507895 (2016).

32. Abdel-Moneim, A. S., Kamel, M. M., Hassan, N. M.: Evolutionary and genetic analysis of human bocavirus genotype-1 strains reveals an evidence of intragenomic recombination. J Med Microbiol 66, 245-254 (2017). 